\title{
STUDY ON DYNAMIC BEHAVIORS AND VIBRATION REDUCTION TECHNIQUES ON CABLE-SUPPORTED RIBBED BEAM COMPOSITE SLAB
}

\author{
Wen-Tao Qiao ${ }^{1, *}$, Dong Wang ${ }^{2}$, Qi An ${ }^{3}$ and Hai-Ying Zhang ${ }^{4}$ \\ ${ }^{1}$ Associate Professor, School of Civil Engineering, Shi JiazhuangTiedao University, China \\ ${ }^{2} P E$, TRC Engineering, Inc, LA, United States \\ ${ }^{3}$ Lecturer, School of Civil Engineering, Qingdao University of Technology, China \\ ${ }^{4}$ Master Candidate, School of Civil Engineering, Shi JiazhuangTiedao University, China \\ *(Corresponding author: E-mail:tottyer@126.com)
}

\section{A B S T RA C T}

Based on the cable-supported structure system, a new-style, highly-efficient and long-span pre-stressed floor structure, namely the cable-supported ribbed beam composite slab (CBS) was put forward. The research on dynamic behaviors of CBS was performed with both FEM and experimental methods. The research results indicate that the base frequency of CBS is low and the distribution of CBS's natural vibration frequencies is uniform and concentrated, the low-order modes are mainly vertical vibrations. Four important parameters of CBS were investigated, and the results show that the influence of the slab thickness and cable diameter on CBS's natural frequency is weak. The base frequency will be enhanced by increasing the sag-span ratio, but this effect is insignificant when the sag-span ratio exceeds 0.05 . Increasing the depth of ribbed beam can boost the natural vibration frequencies, and this can improve the integral rigidity of CBS. Moreover, the low base frequency of CBS is within the frequency range of the pedestrian excitation loads, five pedestrian loads were used in the analysis, and the results indicate that the vibration comfort problem is significant. The tuned mass dampers (TMD) were used to reduce the structural vibration, when the parameters, numbers and locations of TMD are well designed, the pedestrian-induced vibration is reduced significantly and the reduction efficiency is $68.62 \% \sim 84.21 \%$.

\section{ARTICLE HISTORY}

$\begin{array}{ll} & \\ \text { Received: } & 5 \text { June } 2017 \\ \text { Revised: } & \text { 12 October } 2017 \\ \text { Accepted: } & \text { 22 January } 2018\end{array}$

\section{KE Y W O R D S}

Cable-supported ribbed beam; composite slab;

Cable-supported structure;

Dynamic behavior;

Vibration reduction; TMD

Copyright $\odot 2019$ by The Hong Kong Institute of Steel Construction. All rights reserved.

\section{Introduction}

For traditional floor structures, such as reinforced concrete floor, steelconcrete composite floor [1-3], pre-stressed concrete floor [4], reinforced concrete space grid floor [5], the span range is limited. With the development of the social economy, the demands of the large space buildings, such as stadiums, exhibition centers, airport terminals and so on, keep growing, especially the demand of the multi-story large space buildings. To feed the demands, based on the concept of cable-supported structure [6], a new type of pre-stressed long span floor structure, cable-supported ribbed beam composite slab (CBS) is introduced. Fig. 1 shows CBS is a highly efficient space structure which is composed of bottom cables, middle struts and top reinforced concrete ribbed beams. The cable and strut support the slab on top, while the pre-stressed cable gives high stiffness for the whole system. Thus, CBS can reach a longer span.

The reference [7] studies the static properties of CBS, and gives a rational method to determine the initial value of the cable pre-stress. The reference [8] studies the mechanics behaviors of CBS during construction, and introduces a practical construction procedure for CBS. The span of CBS is usually very long, and this makes the global stiffness of CBS low. Thus, pedestrian excitations may cause the strong vibration of CBS which discomforts the occupants. So far, there is very few studies about CBS's dynamic properties, and there is none for the pedestrianinduced vibration comfort problem of CBS. Therefore in this study, firstly both the numerical simulation and experimental methods are used to research the dynamic properties of CBS. Secondly, the univariate analysis of several key parameters is performed to study their influence on CBS's dynamic properties with the FEM model. Finally, a rational vibration reduction method for CBS is studied.

\section{Numerical analysis on features of free vibration of CBS}

\subsection{FEM model}

CBS is a new-style long span floor structure which has not been used in the practical project. Based on an actual project using cable supported beam structure-concrete slab composite floor system, the original floor design is updated to a new floor system using CBS. The modified floor design includes 14 pre-stressed cables, and Fig. 2 shows the major dimensions. The precast RC slab is $100 \mathrm{~mm}$ thick, and the ribbed beam size is $250 \mathrm{~mm} \times 400 \mathrm{~mm}$. Because the ribbed beam section near the cable anchor takes larger force, the beam size is increased to $500 \mathrm{~mm} \times 500 \mathrm{~mm}$. Concrete grade C30 is used for both the slabs and ribbed beams. The $\mathrm{V}$-shape struts are placed at the joining

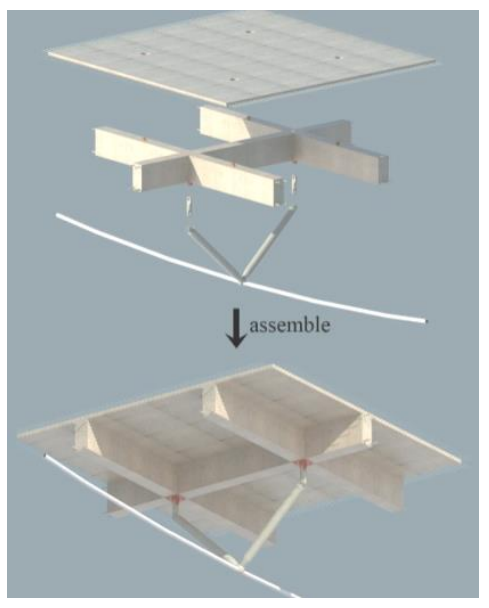

(a) Basic unit

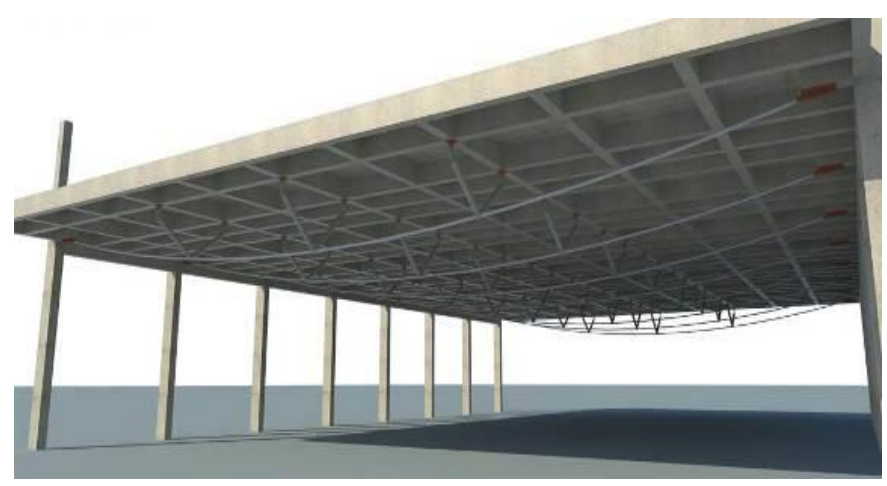

(b) Whole floor structure

Fig. 1 CBS rendering

locations of ribbed beams. The strut section is $159 \times 10$, and its material grade is Q235B. The cable diameter is $100 \mathrm{~mm}$, and its material grade is strand 1570 . 
In this study, MIDAS/Gen is used for the numerical analysis. Plate element is used for the precast RC slabs. Beam element is used for the ribbed beams. Beam element with end in-plane bending restrain released is used for the Vshape struts. Tension only element is used for the cables. To simulate the deformation compatibility condition between the ribbed beams and slabs, the beams and slabs are connected with rigid links. To focus on the dynamic properties of long span floor, the model only includes floor system. Boundary conditions are assumed based on the surrounding members. One end of the span is as rollers, and the other is as pin support. From the columns, only the vertical restrains are considered. Fig. 3 shows the FEM model.

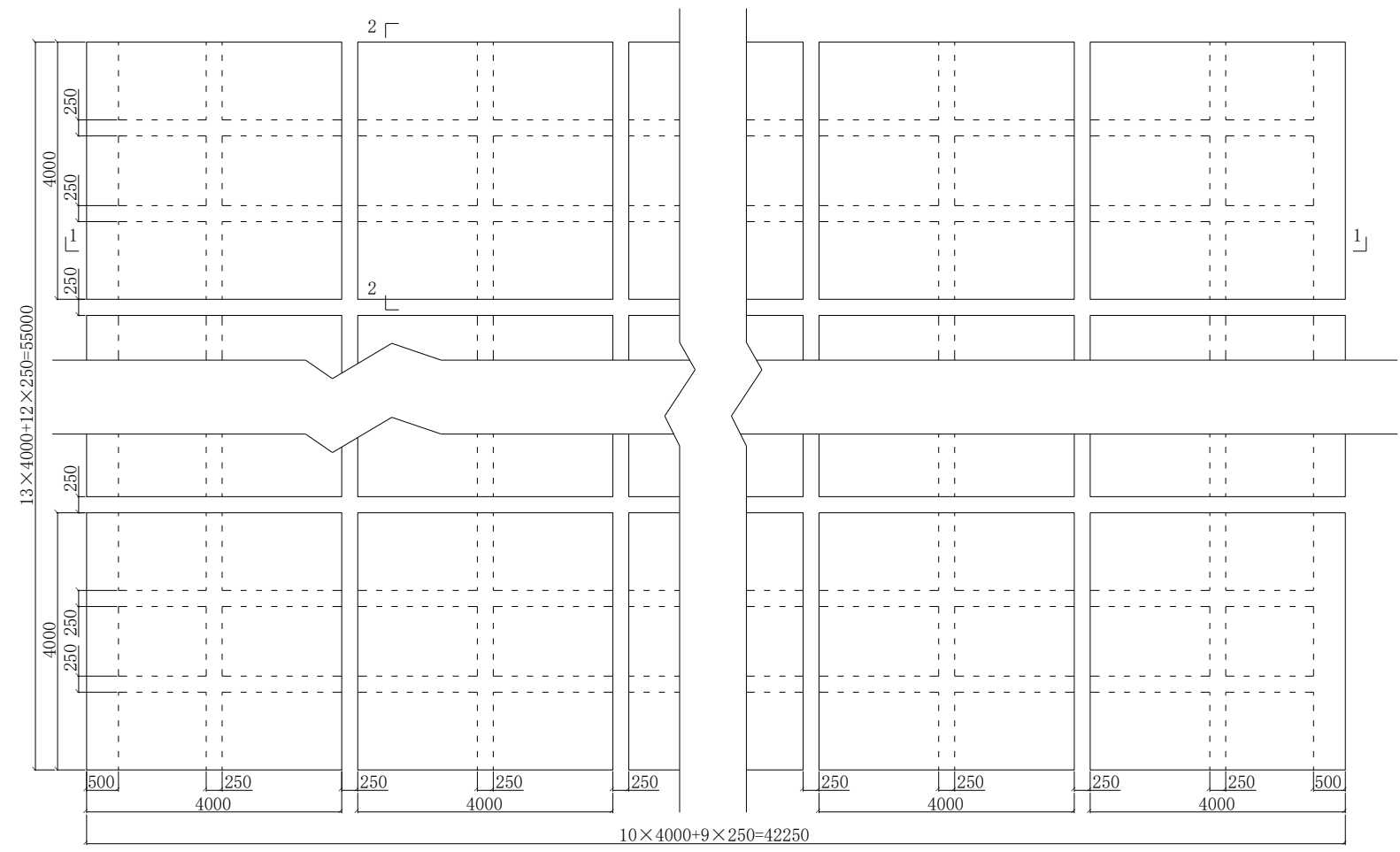

Floor plan

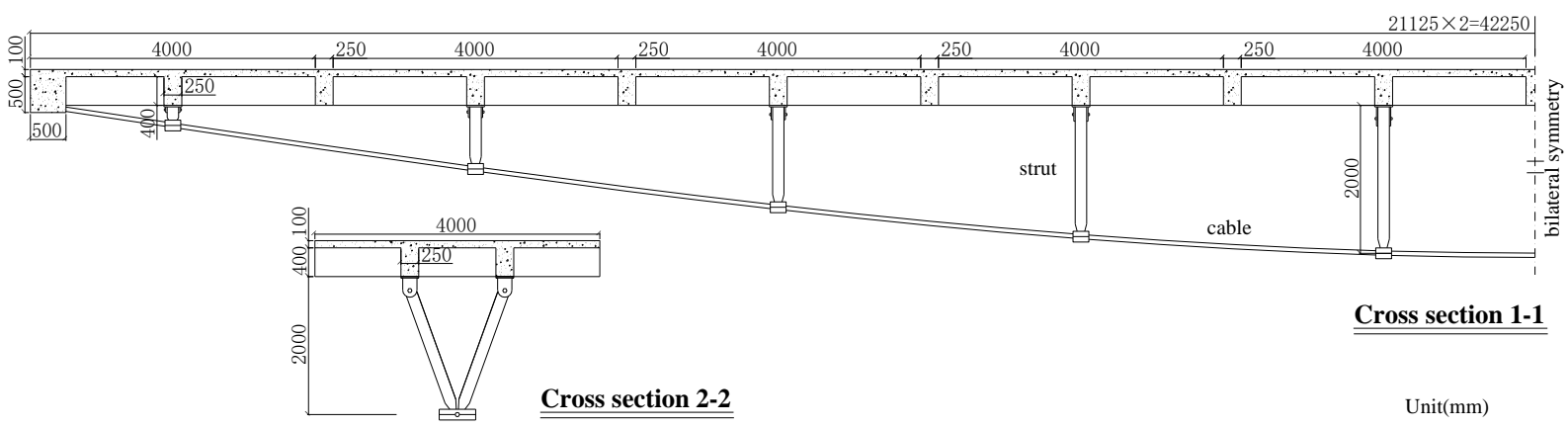

Fig. 2 Model's major dimensions

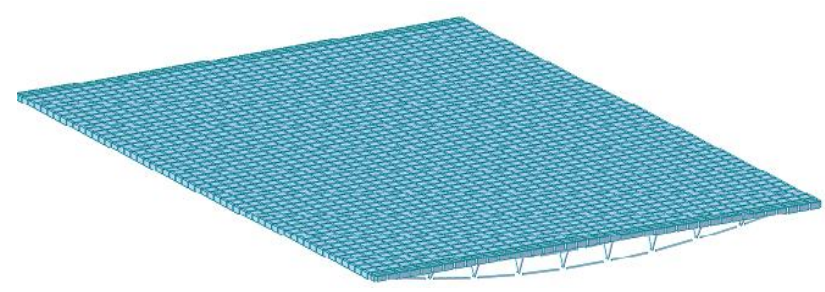

Fig. 3 FEM model of CBS

2.2. Numerical analysis

The initial tension force is determined as $1900 \mathrm{kN}$ with the static equilibrium method [7]. Considering the structure self-weight and the pre-stress, the eigenvalue analysis was performed with the subspace iteration method. The $1^{\text {st }}$ to $30^{\text {th }}$ free vibration frequencies and modes are determined. Fig. 4 plots the 1 st to 30 th free vibration frequencies.

From Fig. 4:

(1) The structure base frequency is low. The $1^{\text {st }}$ frequency is $2.42 \mathrm{~Hz}$.

(2) Looking at the frequency spectrum, the range of the variation is only $12.76 \mathrm{~Hz}$. Especially the frequency increase from $20^{\text {th }}$ to $30^{\text {th }}$ is only $3.07 \mathrm{~Hz}$. This tells that the distribution of CBS's free vibration frequencies is concentrated.

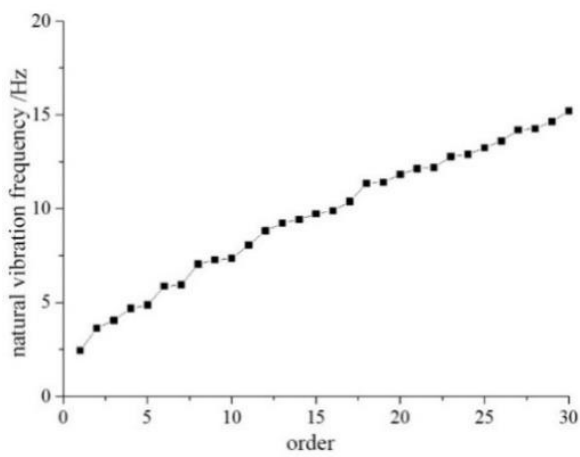

Fig. 4 The first 30 natural vibration frequencies of CBS

The $1^{\text {st }}$ to $3^{\text {rd }}$ free vibration modes are shared in Fig. 5. The free vibration modes reflect the stiffness distribution of the structure.

(1) The $1^{\text {st }}$ mode is the vertical vibration at mid-span. This means the vertical stiffness at mid-span is the weakest.

(2) The $2^{\text {nd }}$ mode shows one cycle of the waveform of vertical deformation along the span, and the $3^{\text {rd }}$ mode shows one and a half cycles. This reflects CBS behaves as a plane in free vibration.

(3) Most of the other modes are symmetric or anti-symmetric vertical vibrations, and only very few are torsional or horizontal vibrations. This tells 
CBS has high torsional and horizontal stiffness

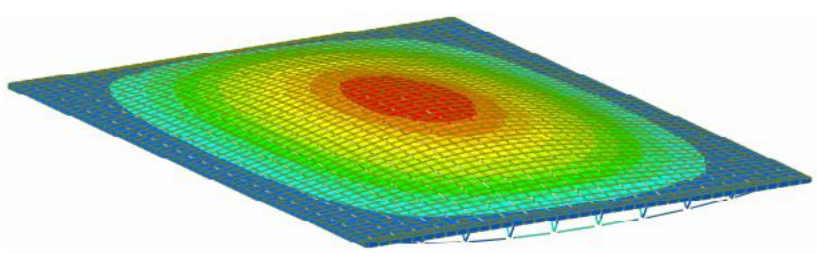

(a)The first mode

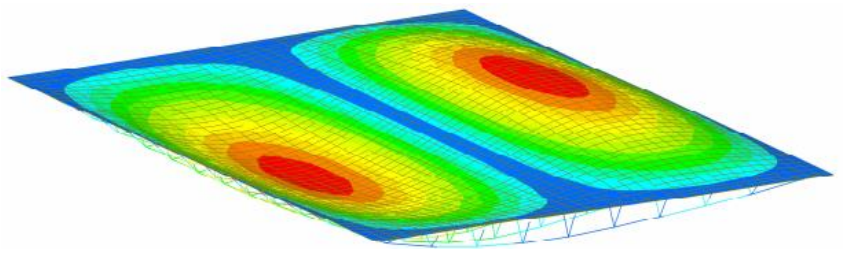

(b) The second mode

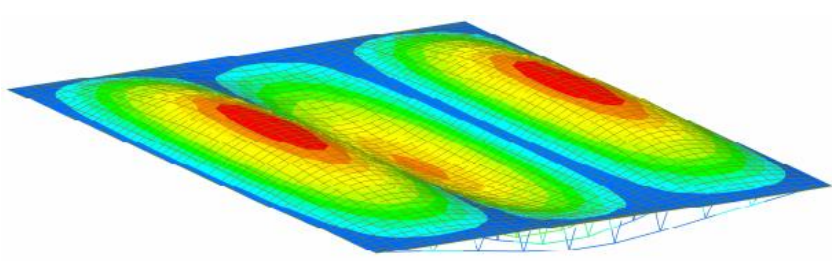

(c) The third mode

Fig. 5 The first 3 order modes

\section{Experimental study on features of free vibration}

\subsection{Test model}

To verify the reliability of the FEM model and the analysis results, the experimental study was performed. Hammer test was performed on a scaled CBS model to determine its free vibration modes and frequencies of the first three orders.

Based on the dimensions of the CBS floor design in section 2, a 1:5 scaled test model with three CBS units (spans) was made. According to the rule of scaled model for engineering experiments, the scaled test model's major dimensions are listed as follows. Span length is $8 \mathrm{~m}$. Cable sag is $0.4 \mathrm{~m}$. RC precast slab length and width are the same as $800 \mathrm{~mm}$ (this does not include length of the doweling rebar). Slab thickness is $20 \mathrm{~mm}$. Concrete grade is C30. The slab transverse rebar is $4 \mathrm{~mm}$ diameter and is spaced as $50 \mathrm{~mm}$. The dowel rebar extends $25 \mathrm{~mm}$ from the slab. Four $40 \mathrm{~mm}$ diameter holes were casted at four corners of the slab. The section of precast RC beam is $50 \mathrm{~mm} \times 80 \mathrm{~mm}$ and the concrete grade is C30. Two $6 \mathrm{~mm}$ diameter grade HRB400 through longitudinal rebar were placed at the top and bottom of the section. The dowel rebar extends $25 \mathrm{~mm}$ from the beam. The beam stirrups were spaced at $40 \mathrm{~mm}$, and the diameter of stirrup is $1.8 \mathrm{~mm}$. M5 bolts were used as shear connector between the beams and slabs, and were embedded at the top of the beam where is corresponding to the hole locations in the slab. $34 \mathrm{~mm} \times 2.5 \mathrm{~mm}$ Q235B steel pipe were used as V-shape struts. Steel plates were placed between the struts and beams, and each steel plate was welded with two steel plates with a hole. The struts were attached to the steel plates with a hole using M14 bolts. Each V-shape strut system has two steel pipes, and the two pipes are connected together on a steel plate using M14 bolt. One $42.5 \mathrm{~mm} \times 2.5 \mathrm{~mm}$ steel pipe was welded at the bottom of the plate, and the cable ran through the pipe. Фs 15.2 (7Ф5) high strength $(\geqslant 200 \mathrm{MPa}$ ) steel strand was used for pre-stress cables. See the scaled model in Fig. 6.

\subsection{Configurations of measure points and excitation points}

Hammer test was used for CBS's free vibration properties. Acceleration transducers, broadband amplifier and data recorder were used in the test. The impact responses of the measure points were recorded using signal data process technique. The free vibration properties of the test model can be determined through analyzing the recorded responses. Fig. 7 show the major equipment used in the test.

FEM model analysis shows that the vertical deformation dominates CBS free vibration modes, so only vertical measure points for acceleration were used which can reveal test model's vertical and torsional vibration. Based on measure point layout principle, nine 941B type vibration pickup sensors were used in this test (see Fig. 8). For each CBS unit, three vibration pickup sensors were placed at span middle and quarter points. Each sensor was attached at the top of the slab using bond particles. For better excitation of hammer impact, the impact location was set at one third point of the middle CBS unit span.

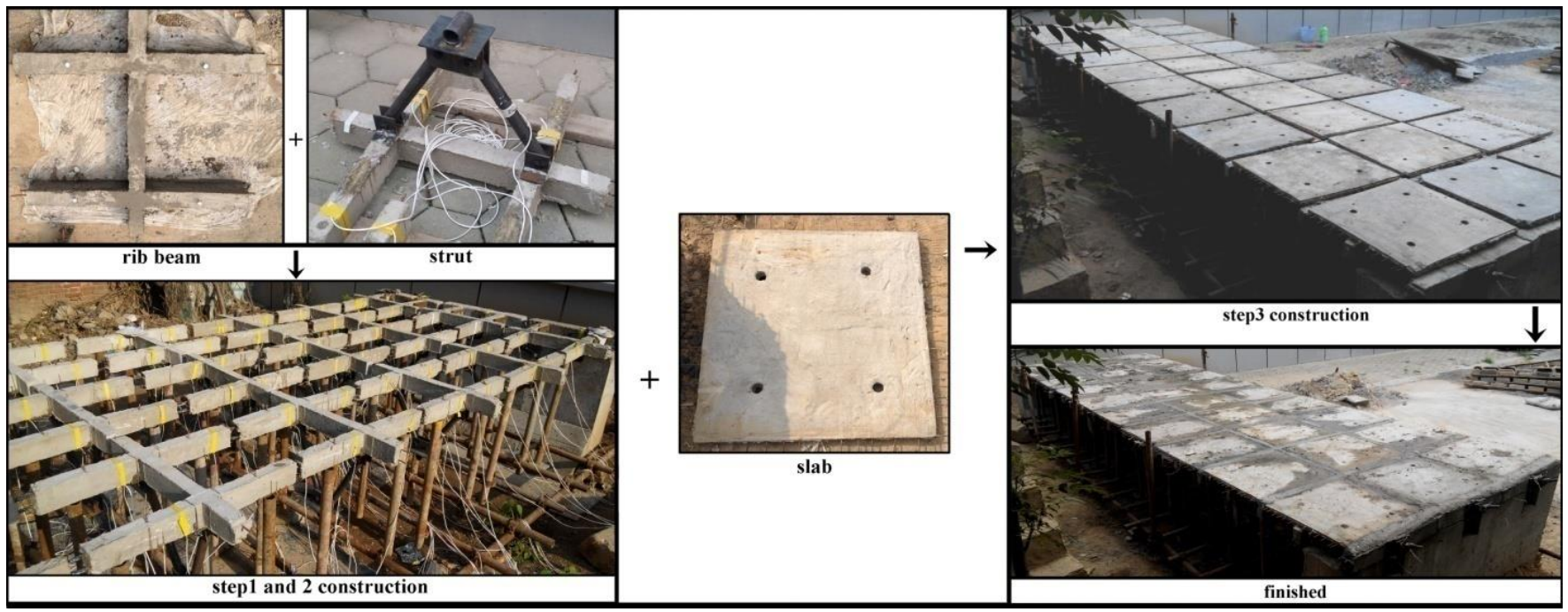

Fig. 6 Scaled test mode 


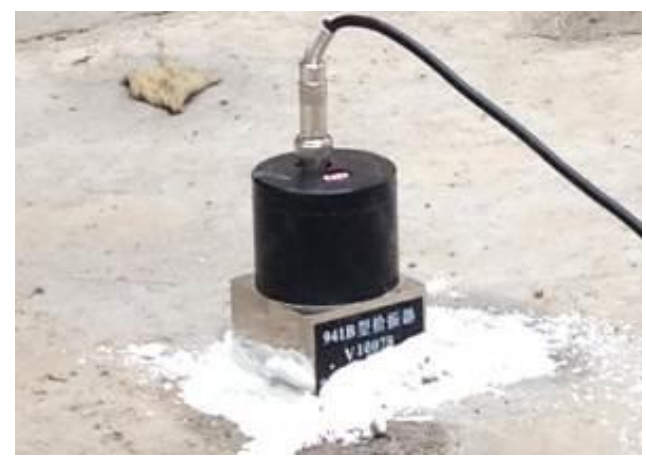

(a) 941B vibration sensor

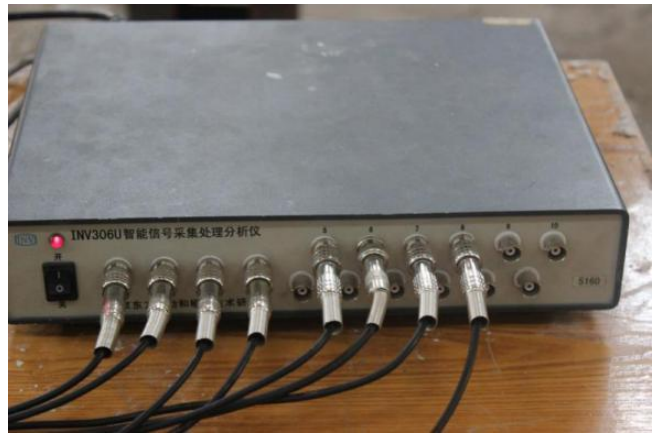

(b) 3018Cdata recorder

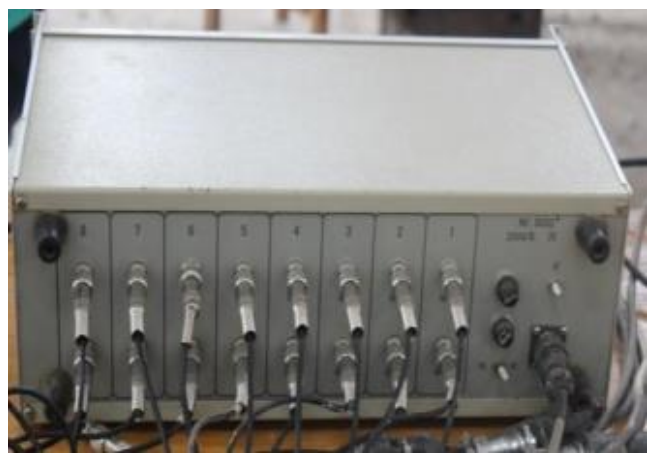

(c) 941 type amplifier

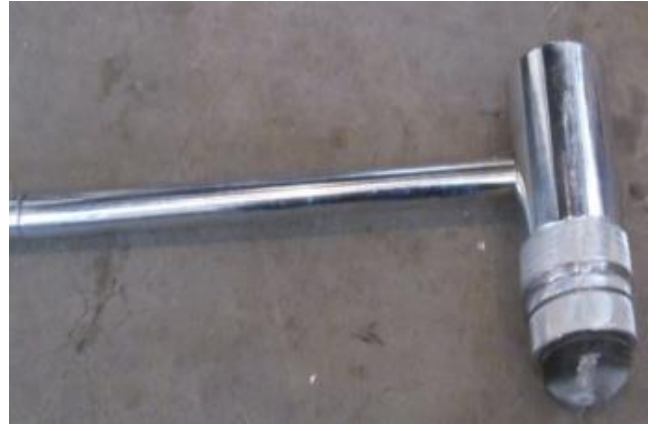

(d)DFC elastic hammer

Fig. 7 Test instruments

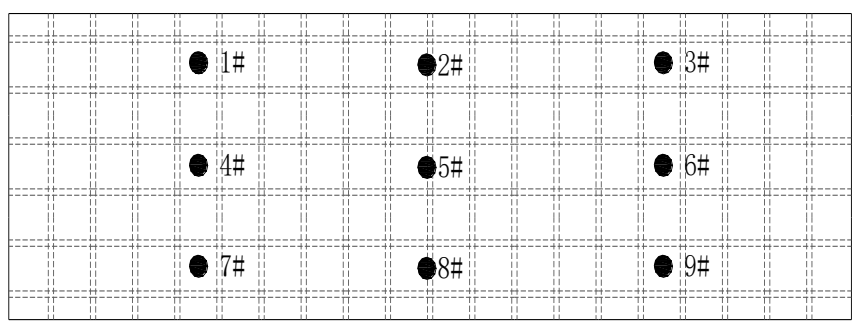

Fig. 8 Measure points distribution

3.3. Experimental results

In the hammer test, the vibration signals from vibration pickup sensors were recorded using automatic signal acquisition unit DASP. DASP recorded the typical wave shapes of each measure point, and the spectrum of the test model under hammer impact was generated using frequency analysis. Peak value method was used to determine the free vibration frequencies of the test model. The high modes' frequencies were not recognizable due to the environmental interferences. Through auto-spectrum analysis and cross-spectrum analysis, the first three modes and frequencies of the test model were obtained (See table 1).

Based on calculation principal of scaling factor of the scaled model, the scaling factor of the frequency between test model and FEM model is $\sqrt{5}: 1$ considering the facts that models used same material and length scaling factor was 1:5.

Table 2 shows the first mode frequency difference between test model and FEM model is $13.2 \%$, while the difference is only $1.1 \%$ for the third mode Table 2 also shows the frequency values from FEM model are all slightly bigger than the experimental values. The mode shapes matched well for the first three modes. The $1^{\text {st }}$ mode shows a half wave shape of vertical deformation. The $2^{\text {nd }}$ mode shows a whole cycle of waveform and the $3^{\text {rd }}$ mode shows one and a half cycles. In a word, the first three modes' frequencies and shapes match well between the test model and the FEM model, and this verifies the reliability of the FEM model and the analysis method used.

Table 1

Test results of free vibration of CBS

\begin{tabular}{lll}
\hline Order & Frequencies $(\mathrm{Hz})$ & Mode shape \\
\hline 1 & 4.71 \\
2 & 5.90 \\
3 & 9.72 \\
\hline
\end{tabular}

Table 2

The first 3 free vibration frequencies comparison

\begin{tabular}{cccc}
\hline \multirow{2}{*}{ Order } & \multicolumn{3}{c}{ Free vibration frequencies } \\
\cline { 2 - 4 } & $\begin{array}{c}\text { Calculated } \\
\text { value(Hz) }\end{array}$ & $\begin{array}{c}\text { Analysis } \\
\text { value(Hz) }\end{array}$ & Error(\%) \\
\hline 1 & 2.42 & $4.71(2.10)$ & 13.2 \\
2 & 3.00 & $5.90(2.64)$ & 12 \\
3 & 4.39 & $9.72(4.34)$ & 1.1 \\
\hline
\end{tabular}

Note: the values in parenthesis are calculated from test results according to scaled modeling theory; error $=($ analysis result-calculated value $) /$ analysis result .

\section{Free vibration features parametric study}

There are four major control parameters in CBS design, sag-span ratio, slab thickness, ribbed beam depth and cable diameter. Using the FEM model, the univariate analysis of the control parameters was performed. To study their influence on CBS's dynamic properties, five typical values were used for each parameter.

The $1^{\text {st }}$ to $30^{\text {th }}$ free vibration modes' frequencies were obtained in the analysis. Fig. 9 shows the frequency changes due to variance of each control parameter.

Fig. 9(a) shows the sag-span ratio affects the base frequency significantly, but for $2^{\text {nd }}$ to $30^{\text {th }}$ modes the sag-span ratio variance only slightly affects the frequencies. Thus, the sag-span ratio doesn't have significant influence on frequencies. Fig. 9(b) shows the ribbed beam depth doesn't affect the base frequency. However, it significantly affects the higher order frequencies. Especially from $10^{\text {th }}$ mode to above, the frequency of each mode increases with the increase of the beam depth. Fig. 9(c) and 9(d) show that the slab thickness and cable diameter have very limited influences on frequencies. Also, the free vibration mode shape stays the same (as showed in Fig. 5) with the parameter variance.

In summary, Fig. 9 shows: (1) Base frequency increases significantly with the sag-span ratio increase. However, when sag-span ratio is bigger than 0.05 , the influence of sag-span ratio becomes very little. This means increasing sag- 
span ratio improves the global stiffness of the CBS, but this improvement is limited once the ratio is bigger than 0.05 . Thus, 0.05 is recommended to be used for the sag-span ratio. (2) Under the conditions of adequate structure strength and permitted deformations, increasing ribbed beam depth can improve CBS global stiffness. (3) The influences on global stiffness from slab thickness and cable diameter are negligible. Therefore, the thinner slab and smaller cable can be used to save the cost in practical project.

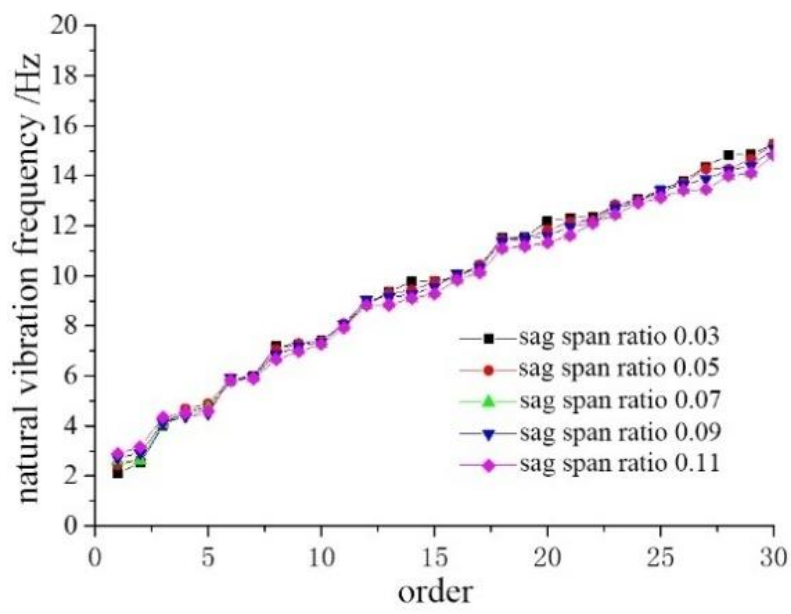

(a) Sag-span ratio influence on free vibration frequencies

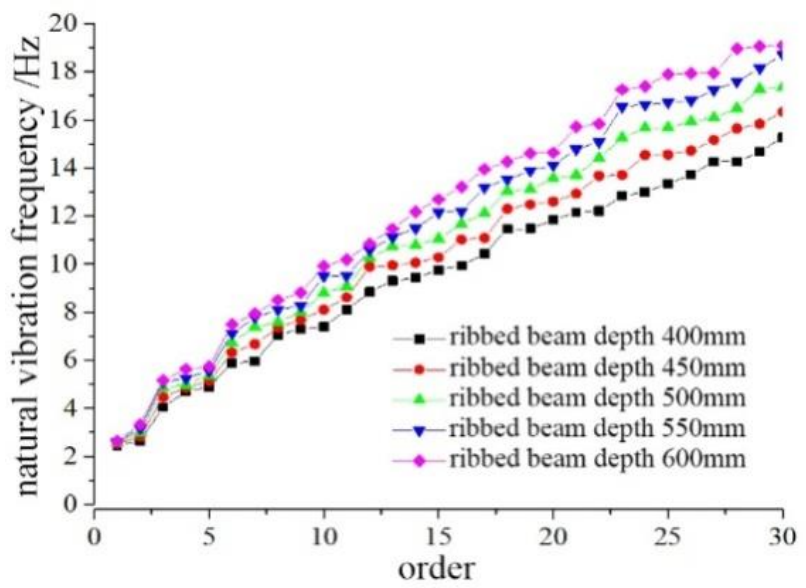

(b) Ribbed beam depth influence on free vibration frequencies

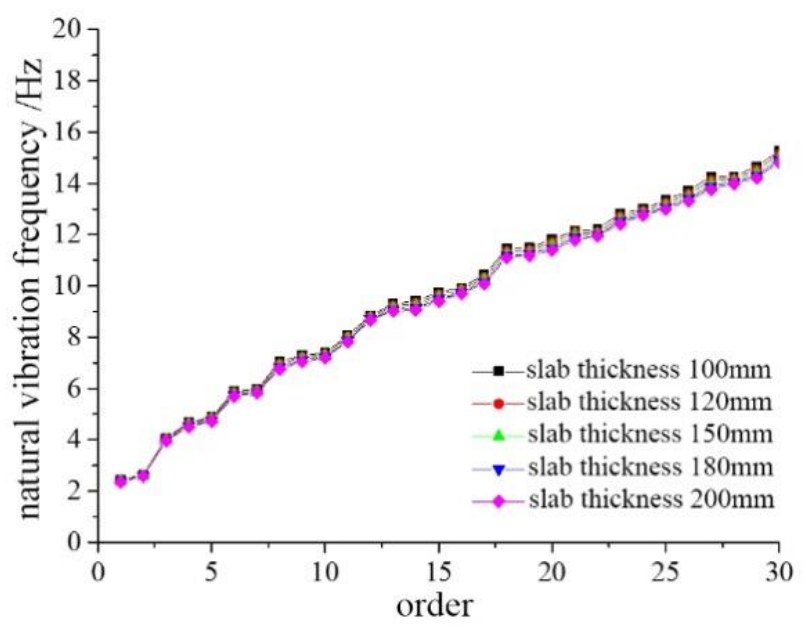

(c) Slab thickness influence on free vibration frequencies

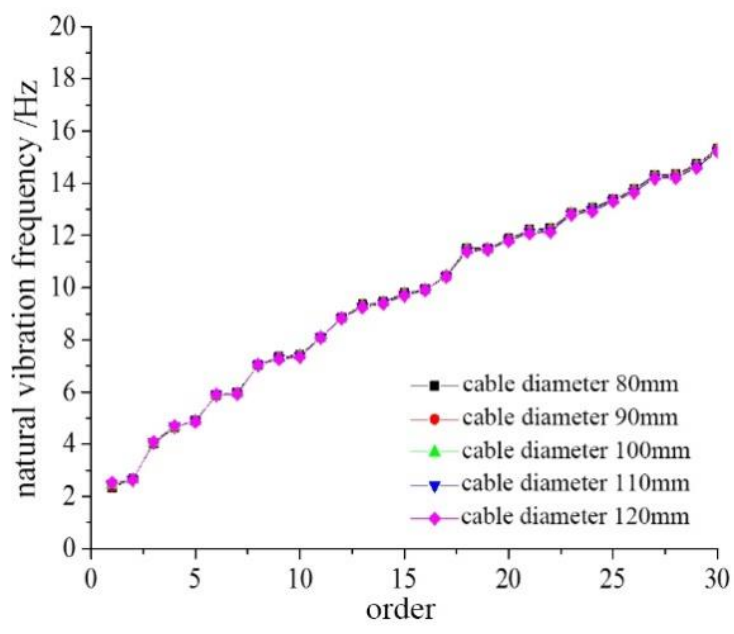

(d) Cable diameter influence on free vibration frequencies

Fig. 9 Parameter influence on free vibration frequencies

\section{Study on vibration reduction}

\subsection{Vibration comfort}

The study on CBS's free vibration characteristics shows that its lower order vibration modes are vertical vibrations and its base frequency is very low. The base frequency of CBS is very close to the pedestrian excitation frequency which is from 1.5 to $3.5 \mathrm{~Hz}$ (walking frequency $1.6 \sim 2.5 \mathrm{~Hz}$, running frequency $2.0 \sim 3.5 \mathrm{~Hz}$, jumping frequency $1.8 \sim 3.4 \mathrm{~Hz}$ ) [9]. Therefore, the pedestrian load will cause resonance of CBS. This resonance of CBS may dissatisfy the vibration comfort requirements on the floor, so the vibration reduction method needs to be investigated for CBS

\subsubsection{Vibration comfort criteria}

In 1997, AISC issued the design criteria for floor vibration. AISC-11 criteria limit the floor vibration acceleration, and its method is currently considered to be one of the most reasonable methods. Fig. 10 shows the human acceptable floor accelerations for different frequencies and different floor usage. Fig. 10 is a double logarithmic plot.

The CBS described in section 2 is used as subject in this section to study the vibration comfort issue of CBS. The structure was assumed to be a sports complex. The AISC-11 criterion is adopted, and the CBS sports complex belongs to the AISC-11 category sports complex with rhythmic activities.

\subsubsection{Model parameter selection}

Elastic modulus of concrete under dynamic loads is bigger than that under static loads. Thus, the modulus of concrete in FEM model is set as 1.2 times of that specified in design code [9]. Structure damping is another critical parameter for structure dynamic analysis. For the CBS floor, referring to ATC 1999 design guidance and considering the influence from the occupancies and activities, the damping ratio is taken as 0.05 . Dead loads considered include structure selfweight and $1.0 \mathrm{kN} / \mathrm{m}^{2}$ floor load. Cable pre-tension load is taken as $1900 \mathrm{kN}$. The effective floor live load is taken as $1.0 \mathrm{kN} / \mathrm{m}^{2}$ which is $1 / 4 \sim 1 / 6$ of the floor live load for normal usage based on engineering experience. The other model parameters, like densities, strengths, are taken as in section 2 .

From modal analysis in section 2.2 , the $1^{\text {st }}$ to $3^{\text {rd }}$ free vibration frequencies are $2.42 \mathrm{~Hz}, 3.00 \mathrm{~Hz}$ and $4.39 \mathrm{~Hz}$, and the first three modes are all primarily vertical vibrations. Although the first three vibration frequencies are all close to pedestrian excitation frequency $1.5 \sim 3.5 \mathrm{~Hz}$, the $1^{\text {st }}$ modal participating mass ratio is $69.87 \%$, while it is $3.04 \%$ for $2^{\text {nd }}$ mode and $11.12 \%$ for $3^{\text {rd }}$ mode. The vibration energy in first mode is much more than that in other modes, therefore the 1 st mode shape is used as the main vibration mode of CBS under pedestrian excitation. 


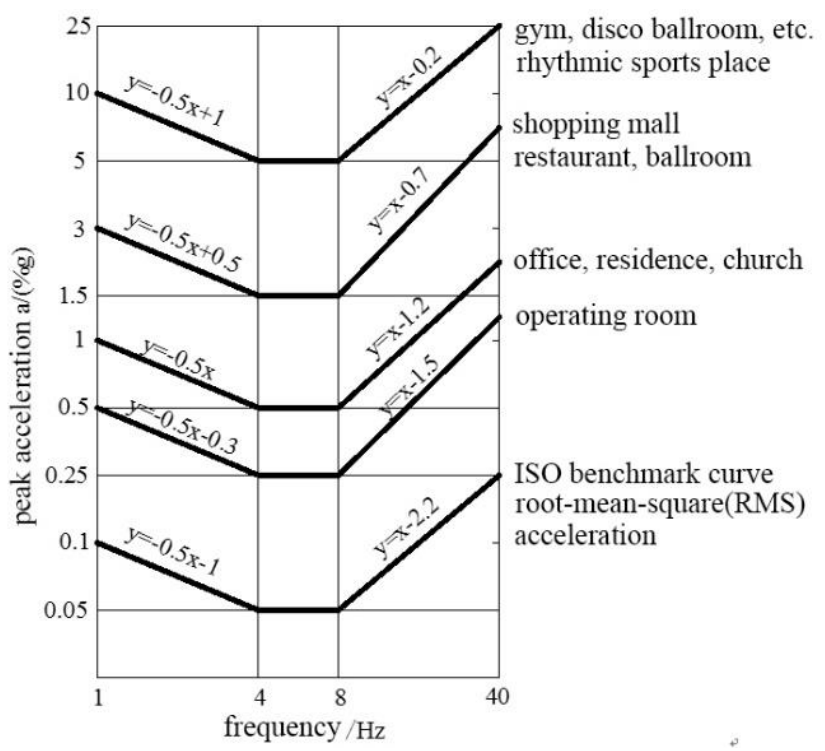

Fig. 10 AISC-11 evaluation criteria

\subsubsection{Pedestrian load cases}

Considering all possible activities in a sport complex, five pedestrian excitation load cases were used in the analysis.

Load case I: Single pedestrian walking. Fourier series load model defined by IABSE was used for single pedestrian walking load (see Eq. 1).

$$
F(t)=G\left[1+\sum_{i=1}^{3} \alpha_{i} \sin \left(2 i \pi f_{s} t+\varphi-\varphi_{i}\right)\right]
$$

Where, $G$ - body weight, $0.7 \mathrm{kN}$ is a common value to use; $\alpha_{i}$-the $i^{\text {th }}$ order load frequency dynamic factor, $\alpha_{1}=0.4+0.15\left(f_{\mathrm{s}}-2\right), \alpha_{2}=\alpha_{3}=1 ; f_{\mathrm{s}}-$ pedestrian walking frequency; $\varphi_{1}$ - initial phase angle, $\varphi_{1}=1, \varphi_{2}=\varphi_{3}=0.5 \pi$.

To maximize the floor's vibration response, the walking frequency $f_{\mathrm{s}}$ is taken as $2.42 \mathrm{~Hz}$, which is the $1^{\text {st }}$ free vibration frequency of the CBS floor. Fig. 11 shows time-history graph of the load.

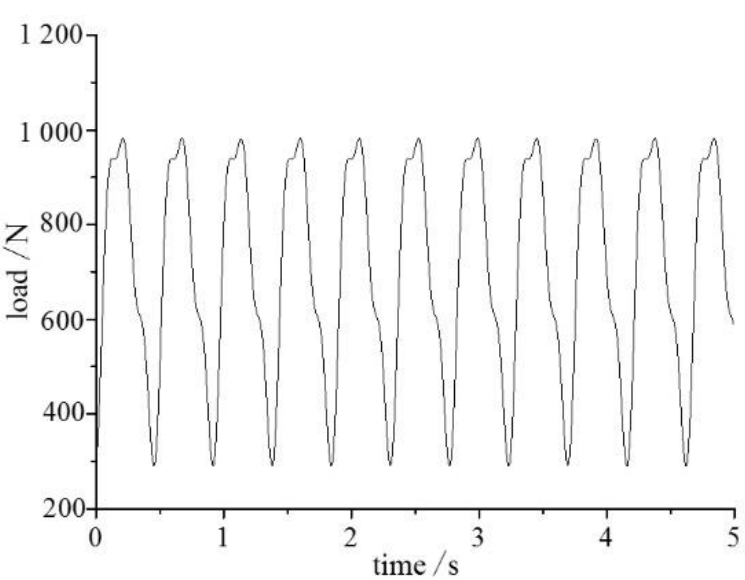

Fig. 11 Load time history curve of case

Load case II: Single pedestrian running. Based on the actual data of the single pedestrian running from Wheerler [10], half sine load curve was used to simulate this load. The running load frequency is taken as $2.42 \mathrm{~Hz}$ the same as the first free vibration frequency of CBS. See Eq. 2 for load expression. Fig. 12 shows the time-history curve of this load.

$$
F(t)=\alpha \cdot G \cdot\left|\sin \left(\pi t f_{\mathrm{s}}\right)\right|
$$

Where, $G$ - body weight, uses $0.7 \mathrm{kN} ; \alpha$-dynamic factor, $2.6 ; f_{\mathrm{s}}-$ running load frequency.

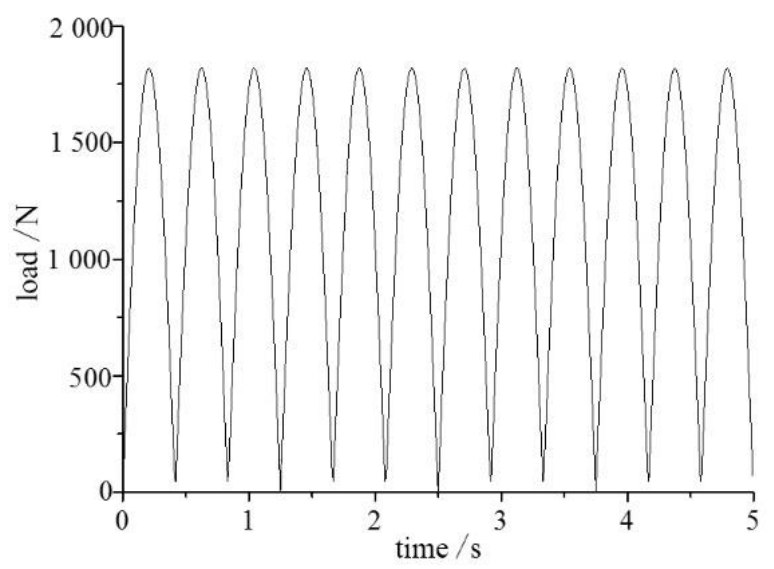

Fig. 12 Load time history curve of case II

Load case III: Single pedestrian jumping. There are few studies on the pedestrian jumping excitation load. The load model defined in BS6399-(1996) is usually used for jumping excitation simulation (see Eqs. 3, 4). $2.42 \mathrm{~Hz}$ was used as the jumping frequency. Fig. 13 shows time-history curve of this load.

$$
\begin{aligned}
& F(t)= \begin{cases}k_{p} \cdot G \cdot \sin \left(\pi t / t_{p}\right) & t \leq t_{p} \\
0 & t_{p} \leq t_{p} \leq T_{p}\end{cases} \\
& F(t)=G\left[1+\sum_{i=1}^{3} \alpha_{i} \sin \left(2 i \pi f_{s} t+\varphi-\varphi_{i}\right)\right]
\end{aligned}
$$

Where, $k_{p}$ - impact load amplification factor; $G$ - body weight, use $0.7 \mathrm{kN}$; $t_{p}-$ duration of foot on the ground in each jumping cycle; $T_{p}$-jumping cycleperiod; $\alpha$-contact ratio, $\alpha=t_{p} / T_{p}$, use $\alpha=1 / 3$ for normal jumping.

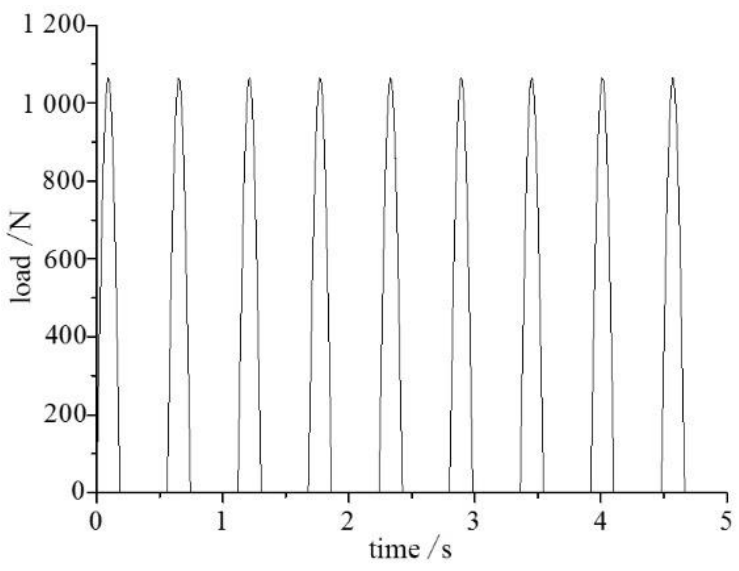

Fig. 23 Load time history curve of case III

Load case IV: Crowd walking. Crowd walking load is very complex because many uncertain factors, such as walking frequencies, phase angles, crowd size and location, individual differences and so on. In most of the studies, the single pedestrian walking load with a crowd factor is used to simulate crowd walking load (see Eq. 5)

$F(t)=m f(t)$

where, $F(t)$ - crowd walking load; $f(t)-$ single walking load; $m$ - crowd factor.

To determine the crowd factor, with the assumptions that pedestrian distribution in a crowd accords with Poisson's distribution and the individual walking phase angle is random, the reference [11] derived the expression of crow factor as Eq. 6

$m=\sqrt{n}$

Where, $n$ means number of individuals in the crowd.

Assume the crowd is very dense as one person per square meter. Based on the floor dimensions showed in Fig. 2, a crowd of 2324 persons can walk on 
the floor. This gives crowd factor $m$ as 48 . The crowd walking frequency is assumed the same as the base frequency of the CBS floor. Fig. 14 shows the time-history curve of this load.

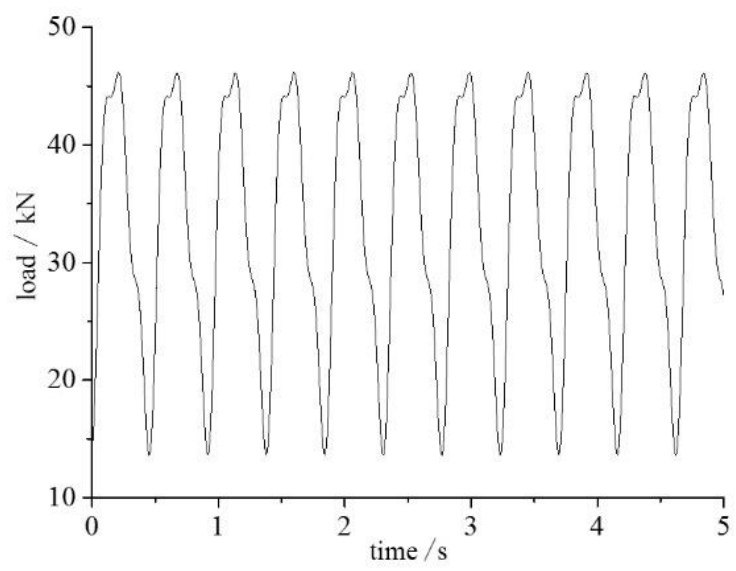

Fig. 14 Load time history curve of case IV

Load case V: Rhythmic activities. The load caused by rhythmic activities can be expressed with a series of simple harmonic waves (see Eq. 7).

$F(t)=w_{p}\left[1+\sum \alpha_{i} \cos \left(2 \pi f_{i} t+\varphi_{i}\right)\right]$

where, $w_{p}$ - equivalent uniform load, see table $3 ; \alpha_{i}$-the $i^{\text {th }}$ order load dynamic factor; $f_{i}$-the $i^{\text {th }}$ order load frequency; $\varphi_{i}$-the $i^{\text {th }}$ order load phase angle, $\varphi_{1}=1, \varphi_{2}=\varphi_{3}=0.5 \pi$.

To maximize the floor vibration response, $f_{i}$ is taken as the base frequency of the CBS floor as $2.42 \mathrm{~Hz}$. Fig. 15 shows the time-history curve of this load.

Table 3

Equivalent uniform loads and dynamic load factors

\begin{tabular}{cccccc}
\hline \multicolumn{2}{c}{ Dance } & \multicolumn{2}{c}{ Aerobic exercise } & \multicolumn{2}{c}{ Concert sports meeting } \\
\hline$W_{p}(\mathrm{kN})$ & $\alpha_{i}$ & $W_{p}(\mathrm{kN})$ & $\alpha_{i}$ & $W_{p}(\mathrm{kN})$ & $\alpha_{i}$ \\
1.2 & 0.5 & 0.2 & 0.6 & 1.5 & $0.05(0.15)$ \\
\hline
\end{tabular}

Where there is no fixed seat in accordance with the value in bracket.

\subsubsection{Comfort analysis}

For the first four load cases, the load was applied at the mid-span as a nodal load. The rhythmic activity load was applied on the floor as a uniform load. The FEM dynamic analysis was performed using MIDAS/Gen, and the maximum accelerations at mid-span for each load case obtained are listed in table 4.

Table 4

Maximum acceleration under each load case

\begin{tabular}{cccccc}
\hline Load cases & Case I & Case II & Case III & Case IV & Case V \\
\hline $\begin{array}{c}\text { Acceleration }\left(\mathrm{m} \cdot \mathrm{s}^{-}\right. \\
2\end{array}$ & 0.011 & 0.015 & 0.038 & 0.621 & 1.144 \\
\hline
\end{tabular}

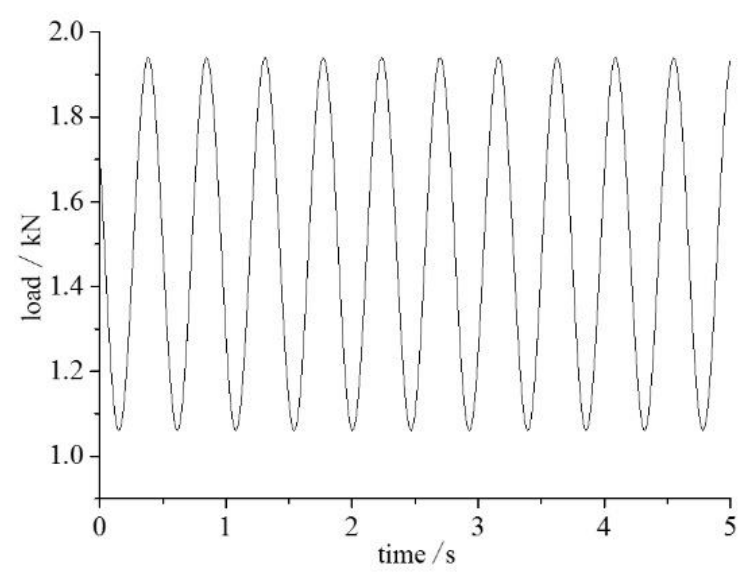

The acceleration limit is determined as $0.53 \mathrm{~m} / \mathrm{s}^{2}$ corresponding to the 2.42 $\mathrm{Hz}$ base frequency of the floor based on AISC-11 floor comfort criteria. For table 4 , accelerations caused by single walking, single running and single jumping are much smaller than the limit. For crowd walking and rhythmic activities, the accelerations are bigger than $0.53 \mathrm{~m} / \mathrm{s}^{2}$. Thus, the comfort issue of CBS under pedestrian excitations is significant and certain vibration reduction method should be applied.

\subsection{Study on vibration reduction}

Tuned mass damper (TMD) is one kind of passive vibration reduction device attached on the main structure (master control member) under control. TMD consists of three parts of mass, spring and energy dissipation damper. The mass is connected with main structure through the spring and damper, which form the main structure-TMD system. Usually the base frequency of the structure is used as master control frequency. If the free vibration frequency of TMD is close to the base frequency of the structure, under dynamic load the mass will move due to inertia force, and the master control member will take the counterforce from the TMD. Therefore, the dynamic response on the structure caused by excitation can be reduced.

Because the floor vibration under pedestrian loads is mainly vertical vibration, the suspended TMD device is installed at the bottom of the ribbed beams to control the floor vertical vibration. The mass is usually made of lead blocks in steel case or steel plates. Either pneumatic spring or normal spring can be used which is set symmetrically in the device. The mass weight and spring stiffness are selected to reach the desired frequency. Viscous damper is used as the energy dissipation damper. The damping can be adjusted by change the piston area or the type of viscous material.

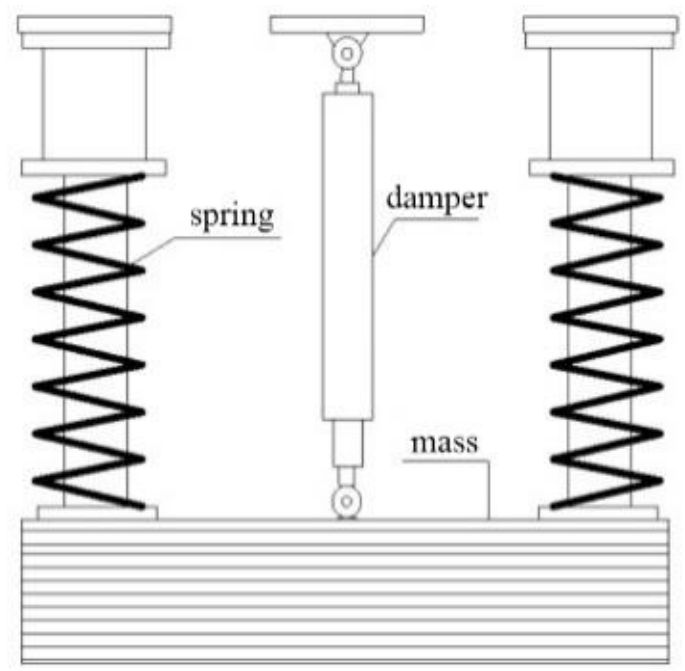

Fig. 16 Suspended-TMD sketch

The advantages of TMD include low cost, easy to install, aesthetically friendly and small space occupancy. As early as in 1966, Lenzen used TMD device as weight as $2 \%$ of the whole structure weight, and the expected vibration reduction was achieved [12]. In 1992, Setare and Haason used TMD to control the floor vibration caused by dancing, and the on-site monitoring verifies the effectiveness of the TMD [13]. In 2008 Beijing Olympics, the conference center in Olympic park has a $60 \mathrm{~m}$ span steel truss roof. The modal analysis shows this long span floor's base frequency is very close to the pedestrian load frequency. The resonant issue can be very significant for the floor. To resolve this issue, 72 TMD devices are used for vibration reduction and they are very effective [14]. For one project using the cable-supported beam and steel composite floor, 24 TMD devices were used on the 40 meter span to reduce the pedestrian-induced vibration and they significantly increase the comfort of the floor [15]. Based on these results from previous studies and projects, TMD was adopted to reduce the pedestrian-induced vibration of the CBS floor in this study.

With reference to the vibration reduction design methods in the previous studies [9, 16-18], DH parameter adjustment method was used to simplify and optimize TMD calculation equations. The optimal stiffness and optimal damping equations for TMD are as follow:

TMD optimal stiffness:

$k_{2}=\omega_{2}^{2} M_{2}=\left(2 \pi f_{2}\right)^{2} M_{2}$

Fig. 15 Load time history curve of case V 
$C_{2}=2 \zeta_{2} M_{2} \omega_{2}=4 \pi f_{2} M_{2} \zeta_{2}$

$f_{2}=\frac{f_{1}}{1+u}$

$\zeta_{2}=\sqrt{\frac{3 u}{8(1+u)^{3}}}$

$\mu=\frac{M_{2}}{M_{1}}$

Where, $C_{2}-$ TMD damping, $f_{1}-$ master control structure's base frequency, $f_{2}-$ TMD free vibration frequency, $K_{2}-$ TMD stiffness, $M_{1}-$ main control structure mass, $M_{2}-$ TMD mass, $\xi_{2}-$ TMD damping ratio, $\mu-$ mass ratio.

From Eqs. 10 and 11, both TMD free vibration frequency $f_{2}$ and the damping ratio $\xi_{2}$ are related to the mass ratio $\mu$. To perform the optimal design of TMD parameters, the mass ratio $\mu$ is determined first, and then the TMD optimal stiffness and optimal damping are calculated with Eqs. 8 and 9. To reach better vibration reduction result, several trials for different $\mu$ were performed to figure out the most reasonable value of $\mu$. On the one hand, bigger value of $\mu$ is preferred for better load-induced vibration reduction. On the other hand, TMD device is extra weight attached on the structure and it is usually connected the locations where have less local stiffness and resonant deformation. TMD installment may introduce too much extra weights and this will affect the serviceability of the structure. Therefore, the weight of TMD device should be limited. Based on previous studies and projects, the value of $\mu$ should be within 0.005 to 0.06 . To maximize the vibration control effect, TMD devices were mounted at the locations showing peak deformations in the $1^{\text {st }}$ free vibration mode of free vibration. Therefore, TMD were placed at the mid-span of the floor. Totally 44 devices were used in 4 rows (see Fig. 17).

The $1^{\text {st }}$ mode participation mass of the CBS model in section 2.2 is about $1030807 \mathrm{~kg}$. 12 values of mass ratio $\mu$ were used, from 0.005 to 0.06 with the increment of 0.005 . Each TMD's mass was set as $M_{l} \bullet \mu / 44$. The worst load case (rhythmic activities) was used in the analysis. The Fig. 18 shows the plot of mass ratios $\mu$ versus the mid-span maximum acceleration.

Fig. 18 tells that the vibration reduction effect gets better along with increasing the mass of TMD. However, this influence becomes insignificant when the value of $\mu$ is bigger than 0.04 . Therefore, $\mu$ as 0.04 is recommended in this study. Table 5 shows the major design parameters of TMD. Fig. 19 shows the curves of mid-span dynamic responses with/without the TMD for different load cases. Table 6 shows the comparison on the peak accelerations with/without TMD devices.

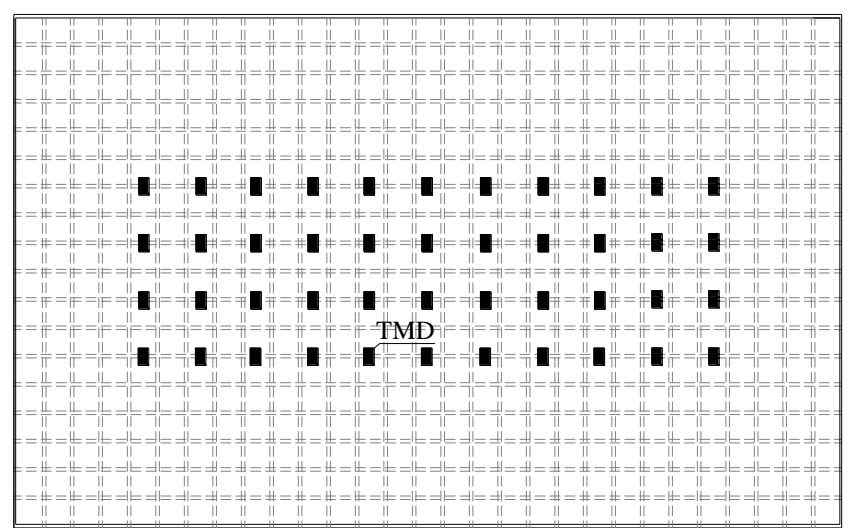

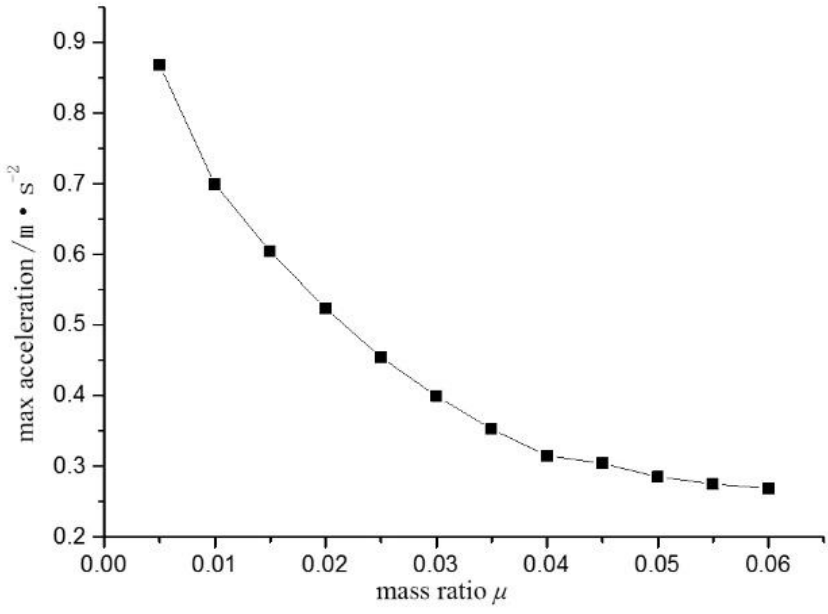

Fig. 18 Max acceleration with different mass ratios

Table 5

TMD parameters

\begin{tabular}{cccc}
\hline Mass ratio & Mass weight $(\mathrm{kg})$ & $\begin{array}{c}\text { Spring stiffness } \\
\left(\mathrm{kN} \cdot \mathrm{m}^{-1}\right)\end{array}$ & $\begin{array}{c}\text { TMD } \\
\text { damping }\left(\mathrm{kN} \cdot \mathrm{s} \cdot \mathrm{m}^{-1}\right)\end{array}$ \\
\hline 0.04 & 937 & 159 & 2.82 \\
\hline
\end{tabular}

Table 6

Max acceleration before and after vibration reduction

\begin{tabular}{cccc}
\hline Load cases & $\begin{array}{c}\text { Max acceleration } \\
\text { before vibration } \\
\text { reduction }\left(\mathrm{m} \cdot \mathrm{s}^{-2}\right)\end{array}$ & $\begin{array}{c}\text { Max acceleration } \\
\text { after vibration } \\
\text { reduction }\left(\mathrm{m} \cdot \mathrm{s}^{-2}\right)\end{array}$ & $\begin{array}{c}\text { Vibration reduction } \\
\text { efficiency }(\%)\end{array}$ \\
\hline Case I & 0.011 & 0.0031 & 71.82 \\
Case II & 0.015 & 0.0029 & 80.67 \\
Case III & 0.038 & 0.006 & 84.21 \\
Case IV & 0.621 & 0.1949 & 68.62 \\
Case V & 1.144 & 0.352 & 69.23 \\
\hline
\end{tabular}

Table 6 shows the vibration reduction effect of TMD devices on CBS floor structure is significant. The vibration reduction efficiency is from $68.62 \%$ to $84.21 \%$. The max accelerations of CBS floor with TMD are all less than 0.53 $\mathrm{m} / \mathrm{s}^{2}$, and the floor comfort requirement is satisfied.

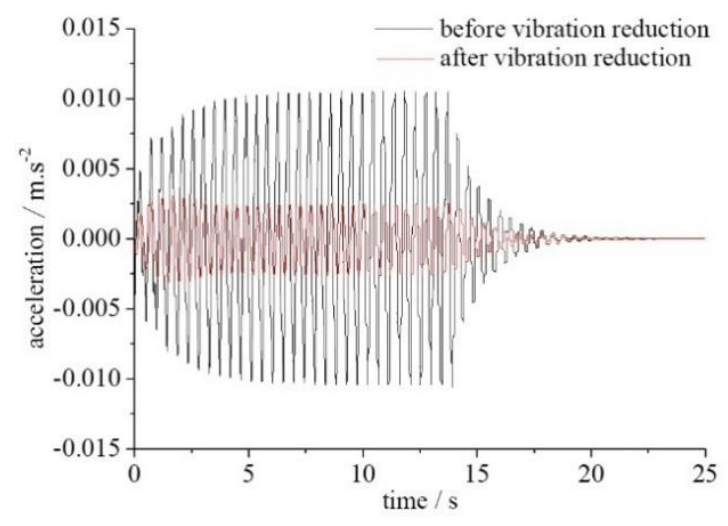

(a) Load case I

Fig. 17 Layout of TMD 


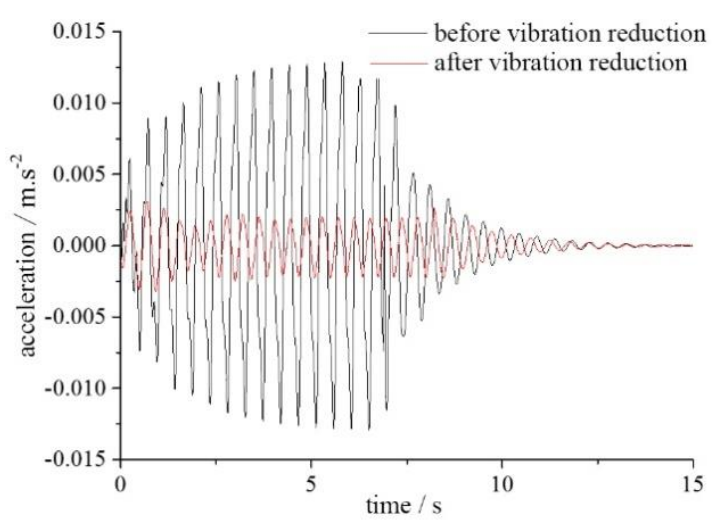

(b) Load case II

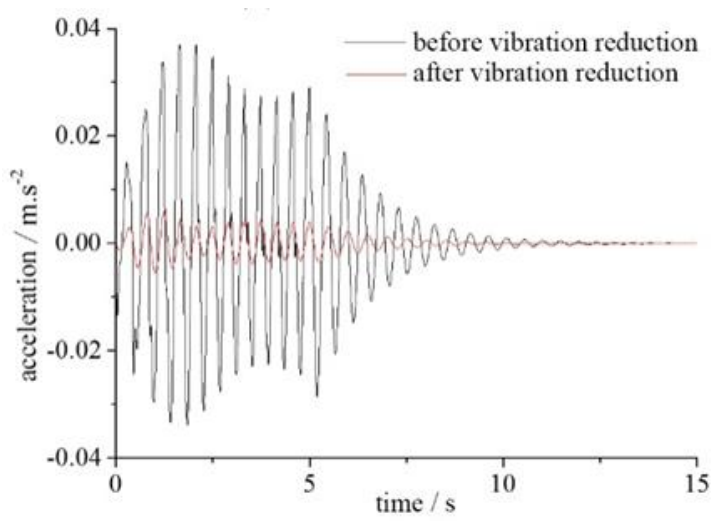

(c) Load case III

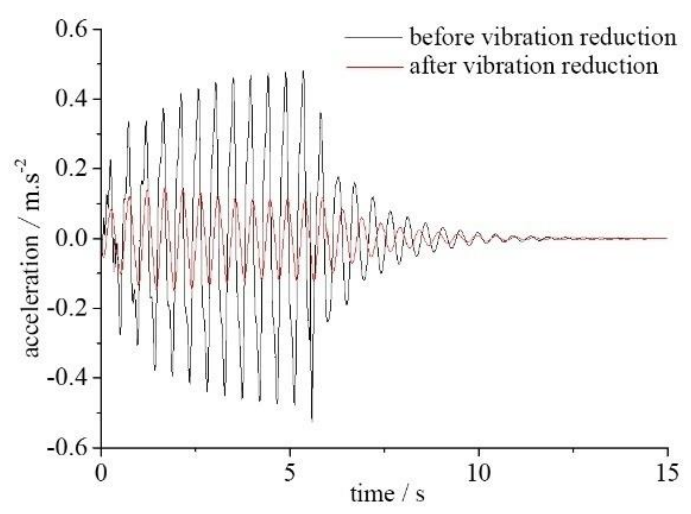

(d) Load case IV

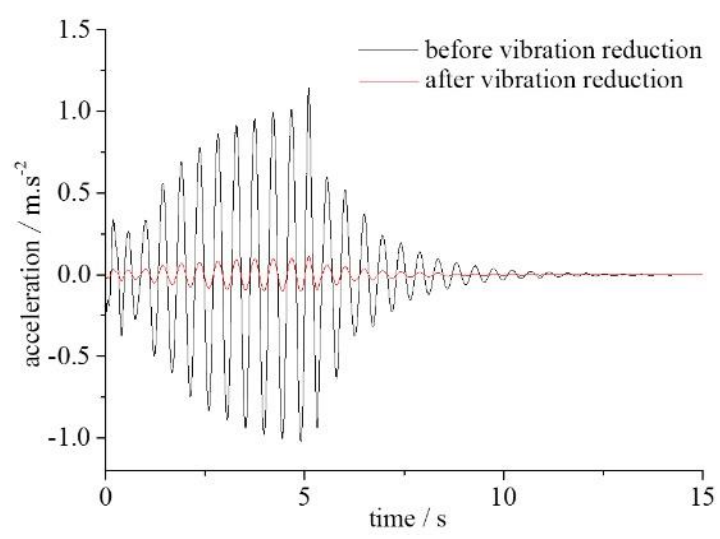

(e) Load case V

Fig. 19 Vibration response curve before and after vibration reduction

\section{Conclusions}

In this paper, the CBS floor system's dynamic properties and vibration reduction technique are studied using both numerical analysis and experimental method. The conclusions are as follows:

(1) The base frequency of CBS floor is relatively low. The frequencies increase uniformly from lower mode to higher mode and concentrate in a small range. The lower modes are mainly vertical vibrations, and then the torsional vibrations show up in the higher modes. There is rarely horizontal vibration in vibration modes. This tells that the vertical stiffness of the CBS is the lowest, the torsional stiffness is relatively high and horizontal stiffness is the highest.

(2) Parametric analysis shows the slab thickness and the cable diameter have little effect on CBS dynamic properties. The base frequency increases along with increasing sag-span ratio, but this influence is limited. Sag-span ratio of 0.05 is recommended. The depth of the ribbed beam has little effect on the base frequency, but its influence on higher mode's frequencies is significant. Increasing ribbed beam depth can improve the global stiffness of CBS floor. The variance of different parameters doesn't change the vibration modes.

(3) The stiffness of CBS floor is relatively low, and the vibration comfort issue is serious. TMD devices are adopted to limit the vertical vibration of CBS floor. TMD is designed using HD parameter adjustment method. Numerical simulation shows the vibration reduction of TMD on CBS floor is very effective, and the reduction efficiency is from $68.62 \%$ to $84.21 \%$ for different load cases. Therefore, the vibration comfort issue of CBS floor is solved by using TMD devices.

\section{Acknowledgements}

The research described in this paper was sponsored by National Natural Science Fund (51208317), Natural Science Foundation of HeBei Province (E2016210052), Science and Technology Research Key Project in Higher Institutions of Hebei Province (ZD2018250) and especially supported by Large Infrastructure Disaster Prevention and Mitigation Collaborative Innovation Center of Hebei Province.

\section{References}

[1] José G.S.D.S., Sebastio A.L.D.A. and Elvis D.C.L., "Parametric modelling of the dynamic behavior of a steel-concrete composite floor", Journal of Engineering Structures, 75(75), 327-339, 2014.

[2] Mello A.V.A., Silva D.J.G.S., Vellasco S.D.P.C.G., Andrade D.S.A.L. and Lima D.L.R.O., "Dynamic analysis of composite systems made of concrete slabs and steel beams", Journal of Constructional Steel Research, 64(10), 1142-1151, 2008.

[3] Lee K., Lee S.H., Kim G.C. and Woo S.S., "Global vertical resonance phenomenon between steel building and human rhythmic excitations", Journal of Constructional Steel Research, 92(1), 164-174, 2014

[4] Pavic A., Reynolds P., Waldron P. and Bennett K., "Dynamic modelling of post-tensioned concrete floors using finite element analysis", Journal of Finite Element in Analysis \& Design, 37(4), 305-323, 2001.

[5] Chanaka M.A., David P.T and Nimal J.P. "Dynamic performance characteristics of an innovative Hybrid Composite Floor Plate System under human-induced loads", Journal of Composite Structure, 2013, 96(4), 590-600

[6] Sun G.J., Chen Z.H. and Longman R.W., "Numerical and experimental investigation of the dynamic characteristics of cable-supported barrel vault structures", Journal of Mechanics of Materials and Structures, 8(1), 1-13, 2013.

[7] Qiao W.T., Li Y., and Deng Y.Z., "Study on mechanical behaviors of cable-supported ribbed beam composite slab strcture", Proceedings of the 14th World Conference on Modern Structural Engineering, Tianjin, 520-525, 2014.

[8] Qiao W.T., An Q., Wang D. and Zhao M.S., "Study on mechanical behaviors of cablesupported ribbed beam composite slab structure during construction phase", Journal of Steel Composite Structure, 21(1), 177-194, 2016.

[9] Lou Y., Huang J., and Lv Z.C., "The vibration comfort design of floor system”, Beijing: Science Press.

[10] Wheerler J.E., "Prediction and control of pedestrian induced vibration in footbridges", Journal of Structural Division-ASCE, 108(9), 2045-2065, 1982

[11] Matsumoto Y. and Griffin M.J., "Mathematical models for the apparent masses of standing subjects exposed to vertical whole-body vibration", Journal of Sound \& Vibration, 260(3), 431-451, 2003.

[12] Lenzen K.H., "Vibration of steel joist-concrete slab floors", AISC Engineering Journal, 3(3), 133-136, 1966.

[13] Setareh M. and Hanson R.D., "Tuned mass dampers for balcony vibration control”, Journa of Structural Engineering, ASCE, 118(3), 723-740, 1992.

[14] Zhu M.,Zhang Z.Q., Ke C.H., et al., "Study on improving people's comfortableness on large-span steel floor structures", Journal of Building Structure, 38(1), 72-76, 2008.

[15] An Q., Chen Z.H., Ren Q.Y., Liu H.B., et al., "Control of human-induced vibration of an innovative CSBS-CSCFS", Journal of Constructional Steel Research, 115, 359-371, 2015

[16] Wendell D.V. and Ronaldo C.B., "Control of vibrations induced by people walking on large span composite floor decks", Journal of Engineering Structure, 33(9), 2485-2494, 2011.

[17] Caetano E.,Cunha Á.,MoutinhoC. and MagalhãesF., "Studies for controlling humaninduced vibration of the Pedro e Inês footbridge, Portugal. Part 2: Implementation of tuned mass dampers", Journal of Engineering Structure, 32(4), 1082-1091, 2015.

[18] Lee S.H., Lee K.K., Woo S.S.and Cho S.H., "Global vertical mode vibrations due to human group rhythmic movement in a 39 story building structure", Journal of Engineering Structure, 57(4), 296-305, 2013. 